\title{
Id-1 expression and prognosis in cancer: do antibodies matter?
}

\author{
Ignacio Gil-Bazo • Mariano Ponz-Sarvisé • Ángel Panizo-Santos • Alfonso Calvo
}

Received: 27 October 2009 / Accepted: 8 November 2009

\section{To the editor:}

We have read with great interest the recently published review by Gomez-Raposo et al. [1] regarding angiogenic factors with prognostic value in ovarian cancer.

As mentioned in the manuscript, inhibitor of differentiation-1 (Id1) has been shown to play a critical role in tumour angiogenesis [2]. Other functions in which Id1 is involved include inhibition of differentiation [3], cell cycle regulation [4] and proliferation [5].

In addition, other reports have suggested the involvement of Id1 in the metastatic process of breast tumours [6] and in chemotherapy resistance $[7,8]$.

However, Id 1 expression pattern in human cancers remains controversial. Using a commercially available non-specific polyclonal antibody, elevated Id1 protein expression levels have been reported in a variety of human cancers, including ovarian carcinoma [9]. Nonetheless, the lack of cell-type specificity of this polyclonal antibody makes it difficult to rely on the reported results $[10,11]$.

Recently, a new highly specific rabbit monoclonal anti-Id1 antibody was developed and tested in different human cancer samples in an attempt to clarify the issue [12]. Surprisingly, the immunohistochemical analysis showed that while the vast majority of breast cancer specimens examined exclusively exhibited a clear endothelial Id1

I. Gil-Bazo (凶) M. Ponz-Sarvisé

Department of Oncology

Clínica Universidad de Navarra

C/ Pío XII, 36

ES-31008 Pamplona, Spain

e-mail: igbazo@unav.es

I. Gil-Bazo · M. Ponz-Sarvisé · A. Calvo

Division of Oncology

Centre for Applied Medical Research (CIMA)

Pamplona, Spain

\author{
Á. Panizo-Santos \\ Department of Pathology \\ Clínica Universidad de Navarra \\ Pamplona, Spain
}

expression pattern, the presence of Id1-expressing tumour epithelial cells was restricted to the subtype of poor prognosis metaplastic mammary carcinomas [12].

Accordingly, we have recently shown Id1 expression in tumour cells in a prostate cancer subset of poor-prognosis patients while no Id1 protein expression was seen in a cohort of good-prognosis prostate cancer tumours [13].

Thus, the reassessment of Id 1 expression using a monoclonal highly specific antibody in other tumours including ovarian carcinomas is warranted. In those future studies, the potential correlation between Id 1 tumour cell expression and prognosis, the association of that expression between primary tumours and metastatic tissues, and the hypothetical involvement of Id1 expression in chemotherapy resistance should be addressed.

Acknowledgement This work has been partially funded by a grant from the Spanish Society of Medical Oncology (SEOM).

\section{References}

1. Gomez-Raposo C, Mendiola M, Barriuso J et al (2009) Angiogenesis and ovarian cancer. Clin Transl Oncol 11:564-571

2. Lyden D, Young AZ, Zagzag D et al (1999) Id1 and Id3 are required for neurogenesis, angiogenesis and vascularization of tumour xenografts. Nature 401:670-677

3. Jankovic V, Ciarrocchi A, Boccuni P et al (2007) Id1 restrains myeloid commitment, Jankovic V, Ciarrocchi A, Boccuni P et al (2007) Idl restrains myeloid commitment,
maintaining the self-renewal capacity of hematopoietic stem cells. Proc Natl Acad Sci U S A 104:1260-1265

4. Ouyang XS, Wang X, Ling MT et al (2002) Id-1 stimulates serum independent prostate cancer cell proliferation through inactivation of $\mathrm{p} 16$ (INK4a)/pRB pathway. Carcinogenesis 23:721-725

5. Di K, Ling MT, Tsao SW et al (2006) Id-1 modulates senescence and TGF-beta1 sensitivity in prostate epithelial cells. Biol Cell 98:523-533

6. Gupta GP, Perk J, Acharyya S et al (2007) ID genes mediate tumor reinitiation during breast cancer lung metastasis. Proc Natl Acad Sci U S A 104:19506-19511

7. Lin JC, Chang SY, Hsieh DS et al (2005) The association of Id-1, MIF and GSTpi with acquired drug resistance in hormone independent prostate cancer cells. Oncol Rep 13:983-988

8. Zhang X, Ling MT, Wang X et al (2006) Inactivation of Id-1 in prostate cancer cells: A potential therapeutic target in inducing chemosensitization to taxol through activation of JNK pathway. Int J Cancer 118:2072-2081

9. Schindl M, Schoppmann SF, Strobel T et al (2003) Level of Id-1 protein expression correlates with poor differentiation, enhanced malignant potential, and more aggressive clinical behavior of epithelial ovarian tumors. Clin Cancer Res 9:779-785

10. de Candia P, Solit DB, Giri D et al (2003). Angiogenesis impairment in Id-deficient mice cooperates with an Hsp90 inhibitor to completely suppress HER2/neu-dependent breast tumors. Proc Natl Acad Sci U S A 100:12337-12342

11. Uehara N, Chou YC, Galvez JJ et al (2003) Id-1 is not expressed in the luminal epithelial cells of mammary glands. Breast Cancer Res 5:R25-R29

12. Perk J, Gil-Bazo I, Chin Y et al (2006) Reassessment of id1 protein expression in human mammary, prostate, and bladder cancers using a monospecific rabbit monoclonal anti-id1 antibody. Cancer Res 66:10870-10877

13. Gil-Bazo I, Ponz-Sarvise M, Rosell D et al (2009) Use of inhibitor of differentiation-1 (Id1) expression (exp) to discriminate good prognosis (GP) from poor prognosis (PP) prostate cancer (PCa). J Clin Oncol [Genitourinary Cancers Symposium] Abstract 12 